Clostridioides (Clostridium) difficile (including epidemiology)

\title{
Multidrug-resistant Clostridium difficile ribotypes 078 and 014/5-FLI01 in piglets from Costa Rica
}

\author{
Mauricio Andino-Molina a, b, c, d, Elías Barquero-Calvo a, c, Christian Seyboldt ${ }^{\mathrm{e}}$, \\ Gernot Schmoock ${ }^{\mathrm{e}}$, Heinrich Neubauer ${ }^{\mathrm{e}}$, Edgardo Tzoc ${ }^{\mathrm{b}}$, César Rodríguez ${ }^{\mathrm{c}, \mathrm{d}}$, \\ Carlos Quesada-Gómez ${ }^{\text {c, d, * }}$ \\ a Escuela de Medicina Veterinaria, Universidad Nacional, Heredia, Costa Rica \\ ${ }^{\mathrm{b}}$ Escuela de Microbiología, Universidad Nacional Autónoma de Honduras, Tegucigalpa, Honduras \\ c Centro de Investigación en Enfermedades Tropicales, Universidad de Costa Rica, San José, Costa Rica \\ d Laboratorio de Investigación en Bacteriología Anaerobia, Facultad de Microbiología, Universidad de Costa Rica, San José, Costa Rica \\ ${ }^{\mathrm{e}}$ Institute of Bacterial Infections and Zoonoses, Federal Research Institute for Animal Health (Friedrich-Loeffler-Institut), Jena, Germany
}

\section{A R T I C L E I N F O}

\section{Article history:}

Received 30 April 2018

Received in revised form

4 November 2018

Accepted 7 November 2018

Available online 8 November 2018

Handling Editor: Vincent Rotimi

\section{Keywords:}

Clostridium difficile

Swine

Multidrug resistance

RT078

RT014/5

\begin{abstract}
A B S T R A C T
Though an overlap of Clostridium difficile PCR ribotypes (RT) in humans and animals has been noted -particularly in piglets-information regarding $C$. difficile isolates from swine is scarce in Latin America. A characterization of $10 \mathrm{C}$. difficile isolates obtained from this origin in Costa Rica revealed the presence of the RT078 $(\mathrm{n}=4)$ and RT014/5-FLI01 $(\mathrm{n}=6)$ ribotypes. Unlike two previous reports from the region, all isolates were multidrug resistant (MDR). According to a minimum spanning tree (MST) analysis, our RT078 isolates formed a clonal complex with some German RT078 isolates and the already noted overlap of RT078 strains in humans and animals. This unanticipated high level of genetic relatedness confirms the transcontinental spread and geographically unlimited clustering of RT078.
\end{abstract}

(c) 2018 Elsevier Ltd. All rights reserved.
Clostridium difficile is a strictly anaerobic, spore forming, Grampositive enteropathogen of relevance to human health high importance in human medicine, with crescent worldwide reports of severe diseases and antimicrobial resistance [1,2]. In veterinary medicine, $C$. difficile has been isolated from different animal species, including production animals such as pigs and bovines [3], and its importance as reservoir and source of infection is still being studied.

Piglets are often colonized in a sub-clinical form with $C$. difficile due to an apparent physiological predisposition [4,5], However, some individuals develop neonatal diarrhea, weight loss and even severe pathologic lesions [6,7].

Human and animal C. difficile isolates from the 078 and 014 PCR ribotypes are highly similar at the genomic level $[8,9]$ and harbor

\footnotetext{
* Corresponding author. Facultad de Microbiología, Universidad de Costa Rica, 11501-2060, San Pedro de Montes de Oca, San José, Costa Rica.

E-mail address: carlos.quesada@ucr.ac.cr (C. Quesada-Gómez).
}

identical accessory genomes and antimicrobial resistance genes [10]. Therefore, is likely that some strains of this pathogen are zoonotic, representing a risk factor for humans [1] that is enhanced by the rather common detection of multidrug resistant (MDR) strains among production and domestic animals [11-14].

The epidemiology and antimicrobial resistance (AMR) of veterinary $C$. difficile from Latin America is largely unknown, except for Brazil, where RT078 and RT014/20 strains of unknown antibiotic susceptibility were isolated from foals and piglets, respectively [15]. To expand this knowledge, we characterized ten $C$. difficile isolates obtained from piglets in two private farms using genetic profiling, MLVA and antimicrobial susceptibility testing. To our knowledge, this study is the first porcine $C$. difficile report in the region and the first report of MDR RT078 in piglets from Latin America.

We obtained rectal swabs from all available piglets in two private reproductive production facilities located in San Jose, Costa Rica in February 2017. Samples of about two grams of fecal content were inoculated and transported in Fastidious Anaerobe Broth (FAB; Lab $\mathrm{M}$ ) for less than $12 \mathrm{~h}$ until processing. A total of 40 


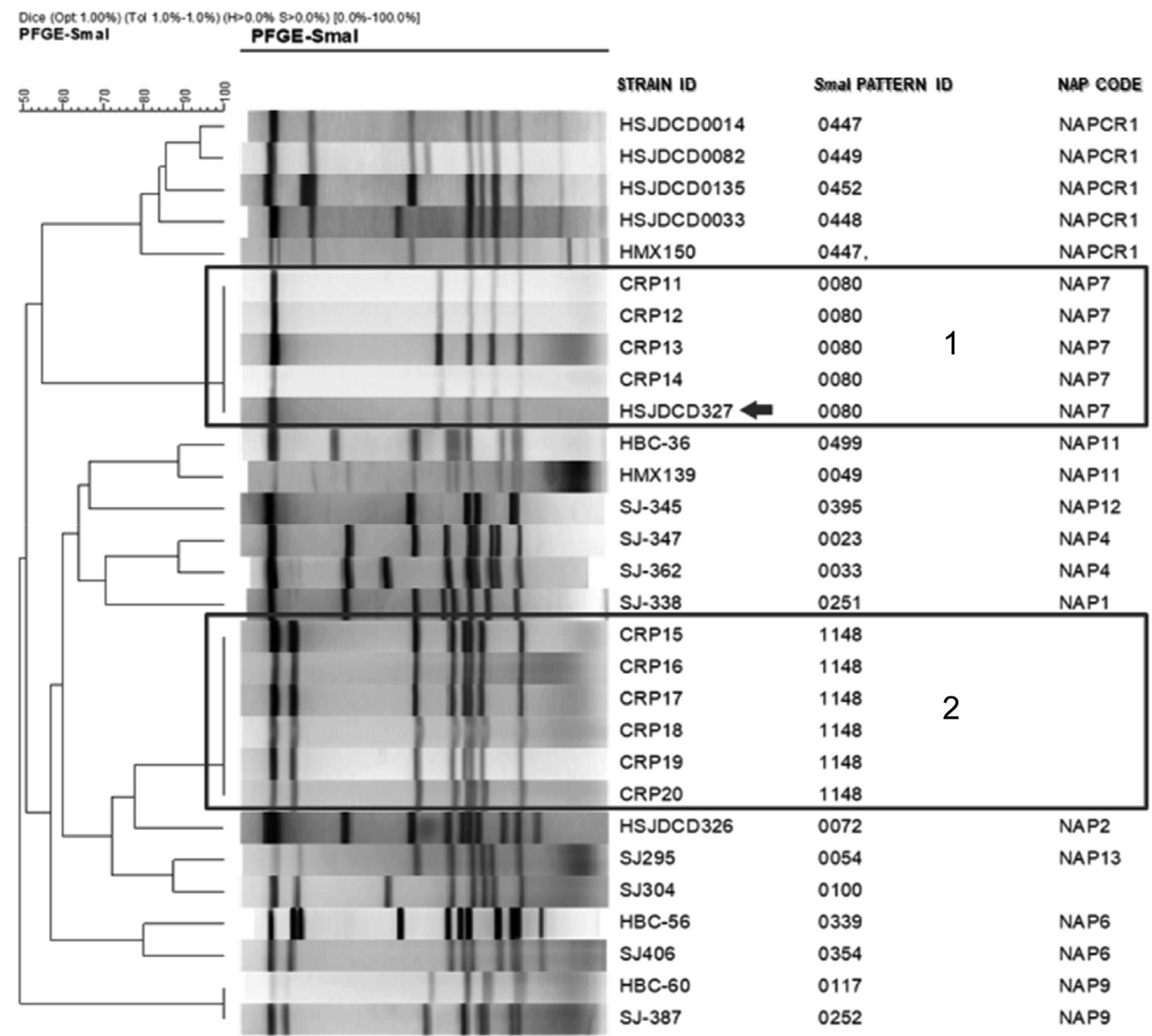

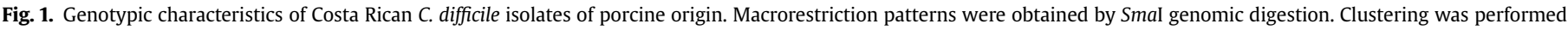

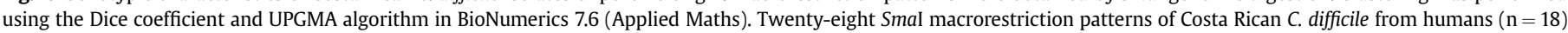

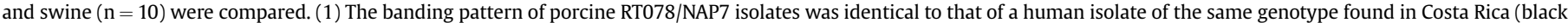

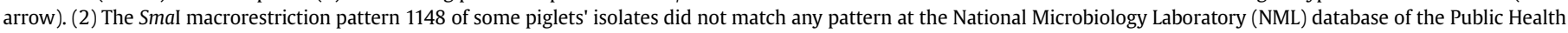
Agency of Canada.

samples were collected from 34 non-diarrheic and 6 diarrheic piglets (2-14 days old). Data regarding farm sizes and husbandry practices was not available. No antimicrobial usage history was reported for the sampled piglets; however, frequent and extensive uncontrolled use of quinolones and cephalosporins is a common practice in Central American husbandry. Sampling and animal handling were carried out in strict accordance with national legislation and the Animal Welfare and Bioethics Committee authorization FCSA-CBAB-EMV-ACUE-005-2016. Owners and veterinarians were informed about the purposes of the study.

C. difficile was recovered from the rectal swabs using a published protocol [16]. Briefly, samples were treated with ethanol shock and then plated onto Cefoxitin-Cycloserine Fructose Agar plates (CCFA; Oxoid) which were incubated under anaerobic conditions. Colonies with classic morphology were further analyzed. This preliminary identification was confirmed using a PCR targeting tpi and $c d d 3$ and toxin gene fragments were also detected by PCR as previously described [17,18].

For Pulsed field gel electrophoresis (PFGE) typing we followed a published protocol [17]. Isolates were assigned with a SmaI macrorestriction pattern and then compared to patterns deposited at the National Microbiology Laboratory (NML) of the Public Health Agency of Canada, database using BioNumerics (Applied Maths) for a NAP assignment. A capillary gel electrophoresis PCR Ribotyping scheme was performed and a seven-loci MLVA protocol was done, supposing interlaboratory comparability and following the laboratory conditions described by Schneeberg et al. [18]. For PCR ribotyping, the resulting peak patterns were analyzed and submitted to the Webribo database (http://webribo.ages.at) for ribotype assignment. Incomplete matches were designated by adding the suffix "/FLI01" to the closest Webribo RT. Minimum spanning trees (MST) were created for the Costa Rican isolates and these bacteria were compared to MLVA types previously published and available for Europe and Asian isolates [18-21] using the BioNumerics software (Applied Maths) with optimized settings [18]. Clonal clusters were defined by a summed tandem-repeats differences (STRD) $<2$. Genetically related clusters were defined by STRD of $>2$ and $\leq 10$; where, single-, double- and triple-locus variants (SLV, DLV and TLV, respectively) were considered [22].

Minimum inhibitory concentrations (MICs) for fourteen antimicrobials from twelve families were determined using Etests (BioMerieux, France) and Brucella agar plates enriched with vitamin $\mathrm{K}$ [1 $\mathrm{mg} / \mathrm{L}]$, haemin [5 $\mathrm{mg} / \mathrm{L}$ ] and defibrinated horse blood [5\%], following the manufacturer's instructions. Breakpoints for ampicillin, amoxicillin + clavulanate, cefotaxime, meropenem, tetracycline, clindamycin, chloramphenicol and metronidazole 
were set according to the CLSI; the moxifloxacin breakpoint was used for quinolones as enrofloxacin is highly used in veterinary medicine in Central America [23]. For vancomycin, the EUCAST cutoff value was used (https://mic.eucast.org/Eucast2/). Breakpoints for amoxicillin, linezolid, and rifampicin were: $\geq 8, \geq 4$ and $\geq 0.004 \mu \mathrm{g} / \mathrm{ml}$, respectively [24]. MDR was defined as resistance to at least three classes of antimicrobials, as recommended by Spigaglia et al. [11]. C. difficile ATCC 700057 was used for quality control purposes.

Ten toxigenic isolates were recovered from the forty rectal swab samples analyzed. Four isolates from non-diarrheic piglets were positive for $t c d A, t c d B$, and $c d t A / B\left(\mathrm{~A}^{+} \mathrm{B}^{+} \mathrm{CDT}^{+}\right)$and showed a $t c d C$ $39 \mathrm{bp}$ deletion. The remaining six isolates, which were obtained from diarrheic piglets, were positive only for $t c d A$ and $t c d B$ $\left(\mathrm{A}^{+} \mathrm{B}^{+} \mathrm{CDT}^{-}\right)$.

Two PCR ribotypes were found among these ten isolates: RT078 $(n=4)$ and PR16677/11282/15501 $(n=6)$; this latter ribotype was designated RT014/5-FLI01 with novel RT patterns. By PFGE, the RT078 isolates were classified as NAP7 and, in line with the ribotyping, the RT014/5/FLI01 isolates represented a new SmaI macrorestriction pattern (1148) without NAP designation (Fig. 1). Two from our six RT014/5-FLI01 isolates were assigned novel RT patterns (PR15501 and PR21160) in the Webrib (Fig. S1) database indicating structural variants. On the contrary, four isolates showed a RT pattern previously reported in the United Kingdom (PR11282), suggesting a possible transcontinental dissemination.

MST analysis of the Costa Rican porcine MLVA types grouped the isolates in two clonal complexes with low intra variability. Clonal complex $1(n=4)$ comprises all isolates from the RT078/NAP7 genotype (STRD $\leq 1, \mathrm{SLV}$ ), including two isolates with identical MLVA types. Clonal complex $2(n=6)$, in turn, embraces all of the RT014/ 5-FLI01 isolates (STRD $\leq 1, \mathrm{DLV}$ ), with five isolates showing identical MLVA profiles (Fig. S2). European, Asian and Costa Rican MLVA types (Table S1) were analyzed to determine their genetic relatedness. Using MST, the Costa Rican RT078 isolates formed one clonal complex with a human German clinical isolate (STRD $\leq 2$, DLV). Moreover, weaker genetically related complexes (STRD $\leq 10$, TLV) with German and Asian porcine isolates were also identified. Overall, variable, but valid, genetic relatedness was found among isolates, regardless of their source or geographical origin (Fig. 2).

All of the isolates showed MICs above established breakpoints to at least three classes of antimicrobials. MIC ranges were high for all resistant isolates, especially for quinolones $(>32 \mu \mathrm{g} / \mathrm{ml})$, clindamycin (RT078: 16-32 $\mu \mathrm{g} / \mathrm{ml}$; RT014/5-FLI01: 6-16 $\mu \mathrm{g} / \mathrm{ml} \mu \mathrm{g} / \mathrm{ml}$ ), tetracycline (RT078: 24-48 $\mu \mathrm{g} / \mathrm{ml}$; RT014/5-FLI01: 48-64 $\mu \mathrm{g} /$ $\mathrm{ml} \mu \mathrm{g} / \mathrm{ml}$ ), and cefotaxime $(>32 \mu \mathrm{g} / \mathrm{ml})$. No resistance was found for the remaining antimicrobials tested (Fig. 3 ).

Antimicrobials like amoxicillin, cephalosporines and enrofloxacin are highly and continuously used in husbandry practices [25-29], therefore it is important to highlight the resistance and high MICs seen for quinolones and cefotaxime. These two antimicrobials have been added by the World Health Organization (WHO) to a list of critically important antimicrobials with highest priority in human medicine and whose usage in veterinary medicine should be reduced or highly controlled [30].

The MDR phenotype detected in our isolates correlates with previous findings from United States [13] and Australia [8] in which high MIC levels were observed too for non-RT078 ribotype with mobile genetic elements or mutated genes [31].

Taking into account our findings, veterinary antimicrobial usage surveillance should be extensively practiced in Costa Rica, as animals have been pointed as possible reservoirs of AMR [14]. Noteworthy, our MDR RT078 strains were genetically related with RT078 strains from Europe and Asia. Surprisingly, one of our porcine isolates clustered with a human isolate, and the other three isolates clustered with porcine isolates from Germany and Japan. Therefore, our MLVA findings corroborate the already noted genetic relationship of RT078/126 strains of different hosts [18-21]. Furthermore, this result matches the already suggested transcontinental dissemination of these strains $[8,20]$.

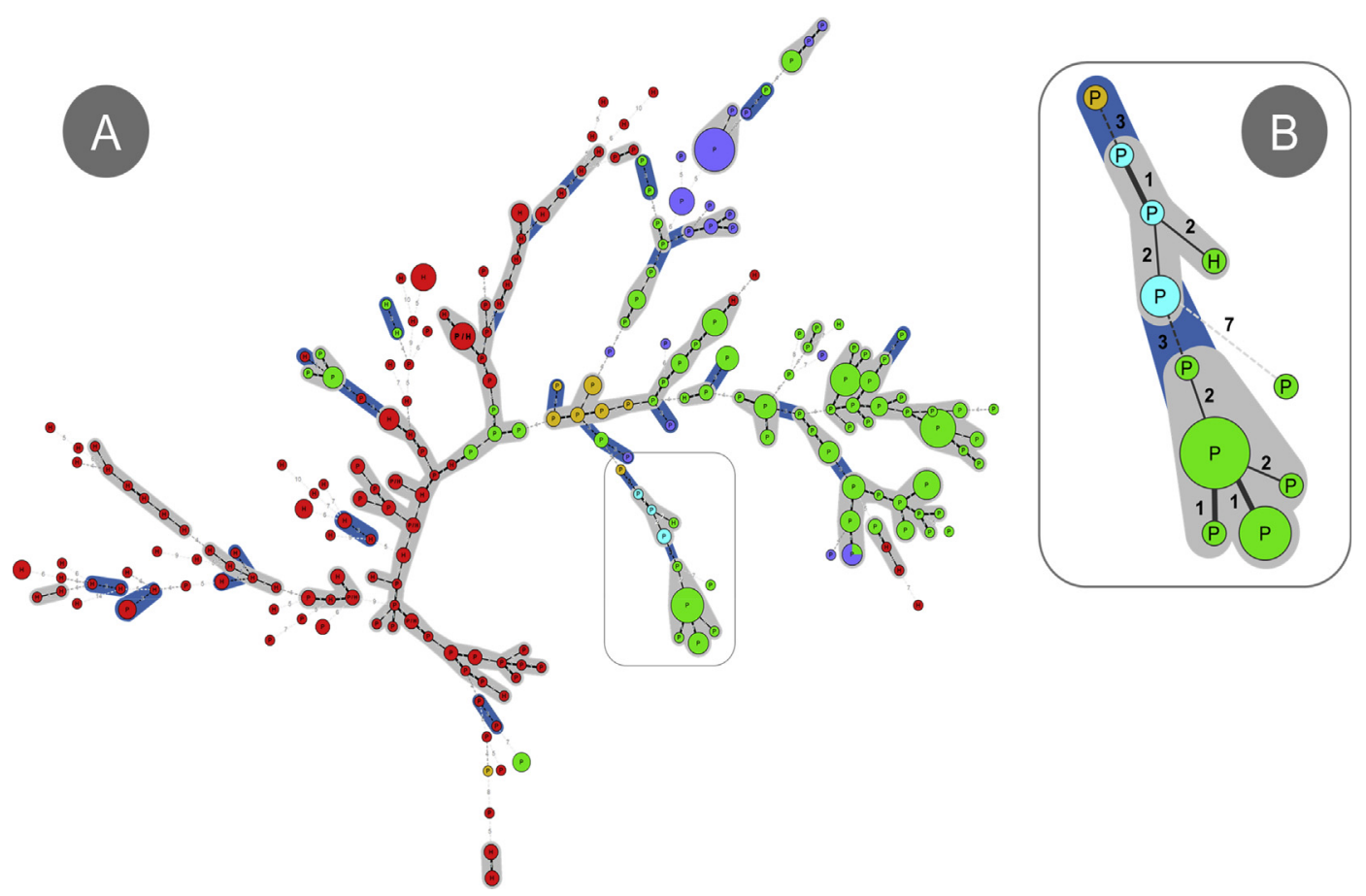

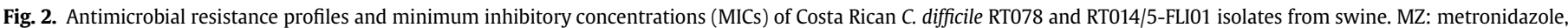

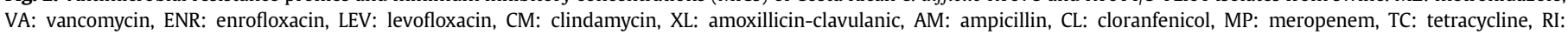
rifampicin, AC: amoxicillin, LZ: linezolid, CT: cefotaxime. 


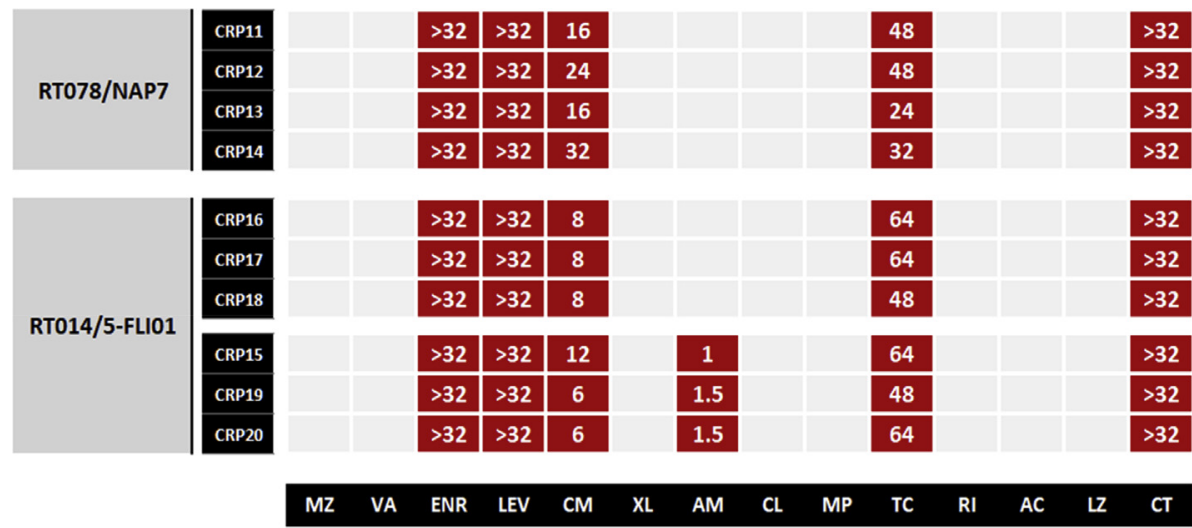

SUSCEPTIBILITY

RESISTANCE

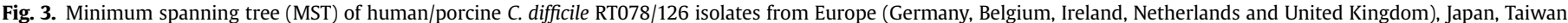

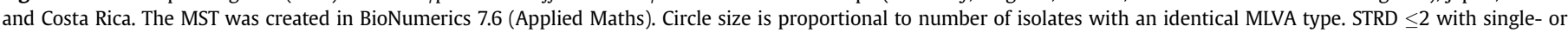

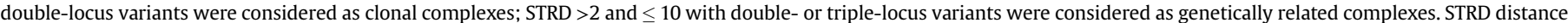

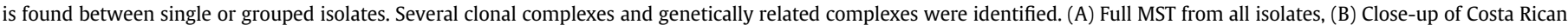
clonal and genetically related complexes.

Our data, even with a small number of isolates, provides a practical baseline for future research, where genomic tools and a larger context should be used for better understanding of $C$. difficile epidemiology. The MDR here reported in both genotypes poses a serious public health concern due the lack of public policies for antimicrobial usage in veterinary in Cost Rica and the region.

\section{Conflicts of interest}

No competing interests.

\section{Acknowledgements}

Caterina Guzmán (PIET, UNA) is acknowledged for her logistics assistance. Pablo Vargas and Robin Cárdenas (LIBA-UCR), Sandra Hennig and Renate Donner (FLI), Dylcia Madrigal and Xindy Víquez (PIET-UNA) are acknowledged for their valuable technical assistance. Tim Du (NML) provided us with access to the NAPGenotyping database and helped us interpreting PFGE patterns. Luis Arroyo, Emily Jiménez, Mónica Madrigal, Olger Murillo and Manuel Campos are acknowledged for their contribution regarding farm and sample access. This study was funded by grants FEESCONARE (0543-15), SIA (0030-09) and the Vice-Rectory of Research of UCR. Mr. Andino-Molina was supported by a DAAD Short-term Grant (57314022).

\section{Appendix A. Supplementary data}

Supplementary data to this article can be found online at https://doi.org/10.1016/j.anaerobe.2018.11.004.

\section{References}

[1] W. Smits, D. Lyras, D. Lacy, M. Wilcox, E. Kuijper, Clostridium difficile infection, Nat. Rev. Dis. Prim. 2 (2016) 16020, https://doi.org/10.1038/nrdp.2016.20.

[2] E. Reigadas, L. Alcalá, M. Marín, A. Martín, C. Iglesias, E. Bouza, Role of binary toxin in the outcome of Clostridium difficile infection in a non-027 ribotype setting, Epidemiol. Infect. 144 (2016) 268-273, https://doi.org/10.1017/ S095026881500148X.

[3] S. Janezic, V. Zidaric, B. Pardon, A. Indra, B. Kokotovic, J. Blanco, C. Seyboldt C. Diaz, I. Poxton, V. Perreten, I. Drigo, A. Jiraskova, M. Ocepek, J. Weese, J. Songer, M. Wilcox, M. Rupnik, International Clostridium difficile animal strain collection and large diversity of animal associated strains, BMC Microbiol. 14
(2014) 173, https://doi.org/10.1186/1471-2180-14-173.

[4] M. Keel, J. Songer, The Distribution and density of Clostridium difficile toxin receptors on the intestinal mucosa of neonatal pigs, Vet. Pathol. 44 (2007) 814-822, https://doi.org/10.1354/vp.44-6-814.

[5] J. Songer, K. Post, D. Larson, H. Jost, R. Glock, Infection of neonatal swine with Clostridium difficile, Swine Health Prod. 8 (2000) 185-189.

[6] M. Keel, J. Songer, The attachment, internalization, and time-dependent, intracellular distribution of Clostridium difficile toxin A in porcine intestinal explants, Vet. Pathol. 48 (2011) 369-380, https://doi.org/10.1177/ 0300985810380395.

[7] J. Songer, F. Uzal, Clostridial enteric infections in pigs, J. Vet. Diagn. Invest. 17 (2005) 528-536, https://doi.org/10.1177/104063870501700602.

[8] D.R. Knight, M.M. Squire, D.A. Collins, T. V Riley, Genome analysis of Clostridium difficile PCR Ribotype 014 lineage in Australian pigs and humans reveals a diverse genetic repertoire and signatures of long-range interspecies transmission, Front. Microbiol. 7 (2016) 2138, https://doi.org/10.3389/ fmicb.2016.02138.

[9] C. Knetsch, T. Connor, A. Mutreja, S. van Dorp, I. Sanders, H. Browne, D. Harris, L. Lipman, E. Keessen, J. Corver, E. Kuijper, T. Lawley, Whole genome sequencing reveals potential spread of Clostridium difficile between humans and farm animals in The Netherlands, 2002 to 2011, Euro Surveill. 45 (2015).

[10] C.W. Knetsch, N. Kumar, S.C. Forster, T.R. Connor, H.P. Browne, C. Harmanus, I.M. Sanders, S.R. Harris, L. Turner, T. Morris, M. Perry, F. Miyajima, P. Roberts, M. Pirmohamed, J.G. Songer, J.S. Weese, A. Indra, J. Corver, M. Rupnik, B.W. Wren, T.V. Riley, E.J. Kuijper, T.D. Lawley, Zoonotic transfer of Clostridium difficile harboring antimicrobial resistance between farm animals and humans, J. Clin. Microbiol. 56 (2018) 1-8, https://doi.org/10.1128/JCM.0138417.

[11] P. Spigaglia, I. Drigo, F. Barbanti, P. Mastrantonio, L Bano, C. Bacchin, C. Puiatti, E. Tonon, G. Berto, F. Agnoletti, Antibiotic resistance patterns and PCRribotyping of Clostridium difficile strains isolated from swine and dogs in Italy, Anaerobe 31 (2015) 42-46, https://doi.org/10.1016/ j.anaerobe.2014.10.003.

[12] D.R. Knight, T.V. Riley, Clostridium difficile clade 5 in Australia: antimicrobial susceptibility profiling of PCR ribotypes of human and animal origin, J. Antimicrob. Chemother. 71 (2016) 2213-2217, https://doi.org/10.1093/jac/ dkw124.

[13] S.N. Thitaram, J.F. Frank, G.R. Siragusa, J.S. Bailey, D.A. Dargatz, J.E. Lombard, C.A. Haley, S.A. Lyon, P.J. Fedorka-Cray, Antimicrobial susceptibility of Clostridium difficile isolated from food animals on farms, Int. J. Food Microbiol. 227 (2016) 1-5, https://doi.org/10.1016/j.ijfoodmicro.2016.03.017.

[14] M.A. Argudín, A. Deplano, A. Meghraoui, M. Dodémont, A. Heinrichs, O. Denis, C. Nonhoff, S. Roisin, Bacteria from Animals as a Pool of Antimicrobial Resistance Genes, Antibiot, Basel, Switzerland, 2017, p. 6, https://doi.org/10.3390/ antibiotics6020012.

[15] R. Silva, M. Rupnik, A. Diniz, E. Vilela, F. Lobato, Clostridium difficile ribotypes in humans and animals in Brazil, Mem. Inst. Oswaldo Cruz 110 (2015) 1062-1065, https://doi.org/10.1590/0074-02760150294.

[16] C. Quesada-Gómez, D. López-Ureña, L. Acuna-Amador, M. Villalobos-Zuniga, T. Du, R. Freire, C. Guzman-Verri, M. Gamboa-Coronado, T. Lawley, E. Moreno, M. Mulvey, G. de Castro, E. Rodríguez-Cavallini, C. Rodríguez, E. Chaves-Olarte, Emergence of an outbreak-associated Clostridium difficile variant with increased virulence, J. Clin. Microbiol. 53 (2015) 1216-1226, https://doi.org/ 
10.1128/JCM.03058-14.

[17] M. Miller, D. Gravel, M. Mulvey, G. Taylor, D. Boyd, A. Simor, M. Gardam, A. McGeer, J. Hutchinson, D. Moore, S. Kelly, Health care-associated Clostridium difficile infection in Canada: patient age and infecting strain type are highly predictive of severe outcome and mortality, Clin. Infect. Dis. 50 (2010) 194-201, https://doi.org/10.1086/649213.

[18] A. Schneeberg, H. Neubauer, G. Schmoock, S. Baier, J. Harlizius, H. Nienhoff, K. Brase, S. Zimmermann, C. Seyboldt, Clostridium difficile genotypes in piglet populations in Germany, J. Clin. Microbiol. 51 (2013) 3796-3803, https:// doi.org/10.1128/JCM.01440-13.

[19] D. Bakker, J. Corver, C. Harmanus, A. Goorhuis, E. Keessen, W. Fawley, M. Wilcox, E. Kuijper, Relatedness of human and animal Clostridium difficile PCR Ribotype 078 isolates determined on the basis of Multilocus VariableNumber Tandem-Repeat Analysis and tetracycline resistance, J. Clin. Microbiol. 48 (2010) 3744-3749, https://doi.org/10.1128/JCM.01171-10.

[20] M. Usui, Y. Nanbu, K. Oka, M. Takahashi, T. Inamatsu, T. Asai, S. Kamiya, Y. Tamura, Genetic relatedness between Japanese and European isolates of Clostridium difficile originating from piglets and their risk associated with human health, Front. Microbiol. 5 (2014) 1-8, https://doi.org/10.3389/ fmicb.2014.00513.

[21] Y.-C. Wu, C.-M. Chen, C.-J. Kuo, J.-J. Lee, P.-C. Chen, Y.-C. Chang, T.-H. Chen, Prevalence and molecular characterization of Clostridium difficile isolates from a pig slaughterhouse, pork, and humans in Taiwan, Int. J. Food Microbiol. 242 (2017) 37-44, https://doi.org/10.1016/j.ijfoodmicro.2016.11.010.

[22] M. Koene, D. Mevius, J. Wagenaar, C. Harmanus, M. Hengsgens, A. Meetsma, F. Putirulan, M. van Bergen, E. Kuijper, Clostridium difficile in Dutch animals: their presence, characteristics and similarities with human isolates, Clin. Microbiol. Infect. 18 (2012) 778-784, https://doi.org/10.1111/j.14690691.2011.03651.x.

[23] Clinical and Laboratory Standards Institute, M100-S27: Performance Standards for Antimicrobial Susceptibility Testing; Twenty-seventh Informational
Supplement, 2017.

24] G. Ramírez-Vargas, C. Quesada-Gómez, L. Acuña-Amador, D. López-Ureña, T. Murillo, M. Del Mar Gamboa-Coronado, E. Chaves-Olarte, N. Thomson, E. Rodríguez-Cavallini, C. Rodríguez, A Clostridium difficile lineage endemic to Costa Rican hospitals is multidrug resistant by acquisition of chromosomal mutations andnovel mobile genetic elements, Antimicrob. Agents Chemother. 61 (2017), https://doi.org/10.1128/AAC.02054-16.

[25] D. Jordan, J.J.-C. Chin, V.A. Fahy, M.D. Barton, M.G. Smith, D.J. Trott, Antimicrobial use in the Australian pig industry: results of a national survey, Aust Vet. J. 87 (2009) 222-229, https://doi.org/10.1111/j.1751-0813.2009.00430.x.

[26] B. Callens, D. Persoons, D. Maes, M. Laanen, M. Postma, F. Boyen, F. Haesebrouck, P. Butaye, B. Catry, J. Dewulf, Prophylactic and metaphylactic antimicrobial use in Belgian fattening pig herds, Prev. Vet. Med. 106 (2012) 53-62, https://doi.org/10.1016/j.prevetmed.2012.03.001.

[27] M. Postma, W. Vanderhaeghen, S. Sarrazin, D. Maes, J. Dewulf, Reducing Antimicrobial Usage in Pig Production without Jeopardizing Production Parameters, 2016, pp. 1-12, https://doi.org/10.1111/zph.12283.

[28] B. Cancho Grande, M.S. García Falcón, J. Simal Gándara, El uso de los antibióticos en la alimentación animal: perspectiva actual, Cienc. Tecnol. Aliment 3 (2000) 39-47.

[29] E. de la Cruz, M. Fournier, F. García, A. Molina, G. Chavarría, M. Alfaro, F. Ramírez, C. Rodríguez, Hazard prioritization and risk characterization of antibiotics in an irrigated Costa Rican region used for intensive crop, livestock and aquaculture farming, J. Enviromental Biol. 35 (2014) 85-98.

[30] F. Scoppetta, M. Sensi, M.P. Franciosini, M. Capuccella, Evaluation of antibiotic usage in swine reproduction farms in Umbria region based on the quantitative analysis of antimicrobial consumption, Ital. J. Food Saf. 6 (2017), https:/ doi.org/10.4081/ijfs.2017.6886.

[31] P. Spigaglia, Recent advances in the understanding of antibiotic resistance in Clostridium difficile infection, Ther. Adv. Infect. Dis. 3 (2016) 23-42, https:// doi.org/10.1177/2049936115622891. 